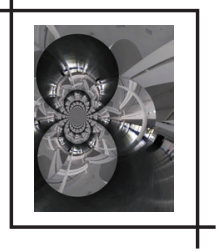

\title{
AFINIDADES AFETIVAS
}

\section{Gabriel Pérez-Barreiro*}

Resumo: Gabriel Pérez-Barreiro foi especialmente convidado pela Revista Trama Interdisciplinar para escrever este artigo sobre a 33a Bienal de São Paulo, curada por ele.

Palavras-chave: Bienal. Afinidades eletivas. Artista-curador. Arte. Arte contemporânea.

Em seu romance As afinidades eletivas, de 1809, Goethe conta a história de um casal aristocrático cuja vida idílica é perturbada pela introdução de dois novos personagens em sua relação: a afilhada da esposa e um amigo de infância do marido. Como costuma acontecer nessas histórias, novas relações são forjadas para além das convenções sociais da época. Até aí, tudo muito típico. Contudo, quando os quatro protagonistas estão na vasta biblioteca desfrutando de uma noite de música e leituras, um deles pega um tratado científico da estante e lê, em voz alta, sobre as reações de certos elementos e moléculas, e como alguns se atraem e outros se repelem, assim como óleo e água. Goethe parece estar nos convidando a traçar um paralelo entre as afinidades eletivas do mundo natural e as conflituosas vidas emocionais e espirituais dos personagens do romance. Se nossos gostos e afinidades são governados por leis que não entendemos totalmente, talvez estejamos diante de um sistema de organização que não é exclusivamente moral ou cultural ou biológico, mas um estranho amálgama dos três, no qual nossas afinidades, sejam elas conscientes ou inconscientes, conduzem-nos.

Quase um século e meio depois, em um Brasil no limiar de uma revolução nas artes (reforçada pela criação da Bienal de São Paulo em 1951), o crítico de arte e ativista político Mário Pedrosa (1996) escreveu sua tese "Da natureza afetiva da forma na obra de arte". Nesse texto, ele usa a teoria da Gestalt para discutir os modos como o espectador ativamente constrói um entendimento de uma obra de arte qualquer, estabelecendo um diálogo entre as características formais da obra e a estrutura psicológica do espectador. A natureza dialética dessa construção e sua adoção tanto da análise formal quanto da subjetividade se mostrariam transformadoras para o desenvolvimento da arte brasileira desde o início dos anos 1950 até

\footnotetext{
* Pérez-Barreiro foi curador da 33ª edição da Bienal Internacional de São Paulo; da 6a Bienal do Mercosul em Porto Alegre em 2007, e de arte latino-americana no Blanton Museum of Art da Universidade do Texas, EUA (2002-2008). É diretor da Collecion Patricia Phelps de Cisneros, em Nova York e Caracas. E-mail: gabriel.perezbarreiro@bienal.org.br
} 
o presente. Simultaneamente enfatizando e relativizando o espectador individual, Pedrosa (1996) articulou uma perspectiva profundamente humanista pela qual é possivel entender a arte e seus efeitos (ou afetos, para usar sua terminologia), independentemente do campo de batalha ideológico dominante no qual uma forma de arte $x$ é considerada inerentemente superior a uma forma de arte $y$. Para Pedrosa (1996), a arte deveria ser julgada essencialmente em termos de sua capacidade de criar uma relação produtiva entre a intenção do artista e a sensibilidade do espectador. Um dos mais importantes ativistas políticos do século XX, Pedrosa (1996) era também bastante claro quanto ao potencial revolucionário da arte dentro dessa estrutura de emancipação individual, resistindo à proposta de uma arte "política" no âmbito de seus conteúdos narrativos.

Eu diria que as ideias de Goethe e de Pedrosa, aplicadas à nossa realidade atual, podem oferecer um modo útil e enriquecedor de pensar os desafios e as contribuições de uma bienal de arte contemporânea. Quando a Bienal de São Paulo foi fundada em 1951, como a segunda bienal internacional depois de Veneza (1895), sua missão era clara: colocar a arte brasileira "em vivo contato" com a produção internacional'. Isso era coerente com a estrutura modernizante e progressista da elite cultural brasileira da época, cuja ambição era combinada com notável savoir-faire e uma força financeira que colocaram o Brasil no mapa da arte internacional quase imediatamente, ao mesmo tempo injetando energia nova na cena de arte local. As primeiras bienais foram organizadas com uma lógica enciclopédica. Como em Veneza, os paises eram convidados a enviar seus "melhores" artistas, mas, diferentemente de Veneza, a Bienal em si organizaria grandes exposições dos maiores artistas da época, incluindo Picasso, Calder, Klee e outros. Além dessas exposições, havia também mostras de arquitetura, design gráfico, joalheria, a chamada arte primitiva, e até arte das missões jesuíticas do Paraguai (6 Bienal).

Alinhada com transformações mais amplas no mundo da arte, a Bienal começou a questionar esse modelo nos anos 1980, momento em que a figura do curador emergia como novo agente organizador em eventos desse tipo. Esperava-se que as bienais agora propusessem algo intencional e que organizassem seus conteúdos segundo essa ideia. Ironicamente, assim como o pós-modernismo se fazia sentir nas artes, trazendo um momento de maior diversidade e de coexistência das linguagens artísticas, a Bienal (e a maioria das bienais do mundo inteiro) movia-se na outra direção, tentando definir ou articular as principais questões e a produção da época, organizar exposições em que o conceito curatorial seria maior que a soma de suas partes (artísticas).

Durante a maior parte de sua história, a Bienal de São Paulo foi uma das poucas de um grupo minúsculo de bienais. Hoje, segundo um levantamento recente, existem cerca de 320

1 - Para uma história das primeiras bienais de São Paulo, ver Alambert e Canhête (2004), Whitelegg (2013) e Nelson (2010). 
bienais ou eventos semelhantes em todo o mundo ${ }^{2}$. A bienal de arte se tornou, em certa medida, o símbolo mais visível do sistema da arte contemporânea: internacional e baseada em eventos, embora tentando chegar a um equilibrio conturbado entre a frivolidade social dos eventos de abertura para a elite do mundo da arte e a estrutura teórica cada vez mais densa de seus postulados curatoriais. Livres dos constantes compromissos programáticos e burocráticos do museu ou do centro de arte contemporâneos, as bienais operam com um privilégio único de potencialmente se reinventar a cada dois anos. Essa aparente liberdade cria dois grandes desafios: para a instituição, existe a dificuldade de manter financiamentos consistentes e uma relação com os públicos locais em nome dos quais esses eventos são organizados, e, intelectualmente, o desafio é como inovar dentro de um modelo que, apesar de sua liberdade, parece frequentemente gerar muitos eventos do mesmo tipo, nos quais conceitos similares são repetidos como parâmetros para muitos dos mesmos artistas.

Eu diria que a crise do modelo tem menos relação com as condições da maioria das bienais, que geralmente são mais livres do que praticamente qualquer outra instituição de arte contemporânea, e mais relação com questões do próprio mundo curatorial em si. Quando, nos anos 1980, o curador começou a emergir como centro do sistema da arte contemporânea, isso levou à ascensão do "curadorismo", a ideia de que a tese curatorial é o motivo e o atributo principal de uma exposição. Naquela época, a ideia de que ser curador (especialmente um curador independente) era até uma profissão viável começou a ganhar força, e diversos programas de graduação em estudos curatoriais foram fundados para servir a esse campo profissional e intelectual florescente. Tendo como modelo uma ênfase quase exclusiva em exposições coletivas temáticas de arte contemporânea, esses programas cimentaram ainda mais a ideia de que uma exposição era, sobretudo, uma oportunidade de propor uma tese, na qual as obras deveriam ser alinhadas para "ilustrar" ou "provar" uma proposição3. Nos anos seguintes desde então, a bienal se tornaria o palco privilegiado em que essas teses podiam ser demonstradas e comparadas.

Voltando a Goethe e Pedrosa, será que os conceitos de afinidade e afeto fornecem uma estrutura ou sistema operacional diferentes, dentro dos quais é possível organizar uma bienal?

Para a 33ª edição da Bienal de São Paulo, proponho que a bienal centralizada, discursiva e de cima para baixo - que hoje é o protocolo padrão para as bienais internacionais - possa evoluir para uma experiência mais diversificada, na qual a hierarquia entre arte e prática curatorial possa ser repensada. Sendo assim, convidei sete artistas para compor a equipe curatorial e organizar uma exposição independente dentro do pavilhão, na qual as próprias obras estivessem incluídas, ao lado das dos artistas de sua escolha. Com esse modelo, espero

2 - Mais informações estão disponiveis em: https://www.on-curating.org/files/oc/dateiverwaltung/issue-39/PDF_to_Download/Oncurating_Issue39_WEB.pdf. Acesso em: 10 jul. 2018.

3 - Para uma crítica ácida dos programas curatoriais, ver Lind (2011). 
mostrar como os artistas constroem suas genealogias e sistemas para entender as próprias práticas em relação às de outros artistas, permitindo ao mesmo tempo que os temas e as relações surjam organicamente do processo da feitura da exposição, em vez de partirem de um conjunto predeterminado de questões. Essa escolha também reflete um desejo de reavaliar a tradição dos artistas como curadores, que é uma parte central da história da arte moderna e contemporânea e também particularmente relevante no Brasil, onde os artistas há muito tempo organizam as próprias plataformas discursivas ${ }^{4}$. Cada artista-curador trabaIhou com total liberdade ao determinar a lista de artistas, o projeto expográfico e a lógica curatorial interna de suas exposições. A diversidade de metodologias curatoriais resultante é inteiramente intencional. Além dessas sete exposições coletivas, escolhi doze projetos individuais de artistas que considero notáveis por diferentes motivos e que não necessariamente têm uma relação temática entre si. Desses doze projetos, três são exposições póstumas de artistas fundamentais dos anos 1990 que não receberam a atenção merecida na história da arte recente: Lucia Nogueira, Aníbal López e Feliciano Centurión. Além deles, o artista Siron Franco participa com uma seleção de sua icônica série Rua 57 (1987), momento transformador na produção do artista e também na história da arte brasileira, em reação a um acontecimento catastrófico do ponto de vista ambiental e social.

Se uma das críticas ao modelo atual das bienais é que existe um descompasso entre os princípios discursivos afirmados e a experiência física efetiva de estar no espaço expositivo, essa questão deveria estar no centro de qualquer proposta de renovação. Para a 33a edição, essa preocupação informa tanto a distribuição física das obras de arte no pavilhão (baixa densidade e espaços expositivos claramente demarcados) quanto o programa educativo. As duas principais bienais brasileiras (a de São Paulo e a do Mercosul) deram grande prioridade à mediação e à educação, e, para mim, essa tradição as distingue da maioria das bienais, nas quais, se essa preocupação existe, geralmente se situa no nível das boas intenções e não se reflete em termos de recursos concretos. Nessa edição, o foco conceitual do programa educativo é a atenção: como administramos ou não nossa capacidade de concentração naquilo que está à nossa volta. Embora essa seja uma preocupação antiga, em nossa época a questão da atenção se tornou especialmente pronunciada. Estamos apenas começando a entender o impacto catastrófico das mídias sociais em nossas vidas interpessoais e políticas. A nossa atenção se tornou o principal produto que as plataformas "livres" tentam revender, enquanto continuam a seduzi-la em nossas horas de vigilia ${ }^{5}$. Aos visitantes da $33^{a}$ Bienal serão

\footnotetext{
4 - Sobre o artista como curador, ver Hoffmann (2004) e Filipovic (2017). No contexto brasileiro, estou pensando em projetos como a revista Malasartes e nas experiências de artistas que deram aulas nos primeiros anos do Museu de Arte Moderna do Rio de Janeiro, assim como em exemplos contemporâneos como o Projeto Fidalga e o Pivô em São Paulo ou a Escola de Arte do Parque Lage no Rio, todas experiências que propõem relações mais horizontais entre artistas e curadores.

5 - Sobre a atenção e seus efeitos políticos contemporâneos, ver Crary $(2014,2017)$ e Lanchester (2017).
} 
oferecidos diversos exercícios ou protocolos, por meio dos quais poderão experimentar de modos diferentes a exposição, na tentativa de compensar a dispersão natural desse tipo de mostra de grande escala. A ênfase na atenção também se associa à noção de Pedrosa (1996) da forma afetiva, estimulando o espectador a criar a própria relação com o objeto e, depois, compartilhar essa experiência com os outros.

0 conceito de Afinidades afetivas opera em dois níveis nessa edição da Bienal. Os projetos dos artistas-curadores demonstram como os artistas podem fornecer um modelo para pensar um tipo de relação entre as obras que surge de relações longas e produtivas dentro do campo em que trabalham. Contudo, ao apresentarmos uma bienal diversificada e fragmentada, livre de uma estrutura temática abrangente, o espectador fica livre para construir a própria experiência das diferentes propostas, sem a sensação de que obterá sucesso ou fracasso à medida que corresponder ou não a um conjunto de princípios centrais e declarados. No cerne dessa edição, há um desejo de reafirmar o poder da arte como lugar único para concentrarmos a atenção no mundo e em favor dele. Se pudermos pensar na arte e em suas exposições essencialmente como experiências, e não como declarações, talvez possamos imaginar uma bienal em que os artistas, curadores e espectadores são tratados como iguais, todos capazes de construir as próprias afinidades afetivas com a arte e com o mundo além dela.

\section{Elective affinities}

Abstract: Gabriel Pérez-Barreiro was specially invited by Trama Interdisciplinar to write this article about the 33rd Bienal de São Paulo, curated by him.

Keywords: Biennial. Elective affinities. Artist-curator. Art. Contemporary art.

\section{REFERÊNCIAS}

ALAMBERT, F.; CANHÊTE, P. Bienais de São Paulo: da era dos museus à era dos curadores. São Paulo: Boitempo, 2004.

CRARY, J. 24/7: late capitalism and the ends of sleep. London: Verso, 2014.

CRARY, J. 24/7: capitalismo tardio e os fins do sono. Tradução Joaquim Toledo Jr. São Paulo: Ubu, 2017.

FILIPOVIC, E. (org.). The artist as curator. London: Koenig Books, 2017.

HOFFMANN, J. (org.) The next documenta should be curated by an artist. Frankfurt: Revolver, 2004. 
LANCHESTER, J. You are the product. London Review of Books, v. 39, n. 16, p. 3-10, Aug. 2017. LIND, M. Hothouse tomatoes and outdoor tomatoes. The Exhibitionist, p. 47-53, May 2011. NELSON, A. Monumental and ephemeral: the early São Paulo bienais. In: O'HARE, M.-K. (org.). Constructive spirit: abstract art in South and North America, 1920s-1950s. Newark: Newark Museum, 2010. p. 127-142.

PEDROSA, M. Da natureza afetiva da forma na obra de arte. In: ARANTES, 0. (org.). Forma e percepção estética: Textos escolhidos 2. São Paulo: Edusp, 1996. p. 105-177.

WHITELEGG, I. The Bienal Internacional de São Paulo: a concise history, 1951-2014. Perspective, v. 2, p. 380-386, 2013. 